Methods From October 2010 to January 2012 (15 months) 18 patients underwent laparoscopic thoracoscopic cardio-oesophagectomy. All 18 patients (12 male, 6 female) had laparoscopic insertion of Freka feeding jejunostomy are included in the study. The feeding jejunostomy was used for feeding from first postoperative day. The standard regime was water at $20 \mathrm{mls} / \mathrm{h}$ on day 1 followed by feed (jevity/osmolyte) at $30 \mathrm{mls} / \mathrm{h}$ on day 2 . The rate of feed was increased at daily increments of $10 \mathrm{mls} / \mathrm{h} /$ day to achieve target rate to meet patient's nutritional requirements. Patients were discharged with feeding jejunostomy in situ, removed at follow-up if nutritionally stable.

Results The average procedure time was $20 \mathrm{~min}$. Median duration of feeding jejunostomy in situ was 3 weeks (range 8 days -6 weeks). Tube related complications, $\mathrm{n}=3$ patients (tube fallout-1, leak-2). Only one of these three patients needed additional parenteral nutrition. There were no procedure or feed related complications. The overall length of stay was not affected by this procedure. The availability of enteral route was useful in $n=2$ patients (chest infection-1, gastric stasis-1) for nutrition longer than the anticipated period.

Conclusion Laparoscopic insertion of feeding jejunostomy is safe, aids early establishment of enteral route for nutrition in patients undergoing cardio-oesophagectomy and useful in providing prolonged nutritional support in patients who develop complications were oral route is not possible.

Competing interests None declared.

\section{Neoplasia (basic science) \\ PMO-088 A LARGE PROPORTION OF COLORECTAL TUMOUR-INFILTRATING CD4+ T CELLS ARE SUPPRESSIVE IRRESPECTIVE OF FOXP3 EXPRESSION}

doi:10.1136/gutjnl-2012-302514b.88

M Scurr, A Gallimore, A Godkin. . Infection and Immunity, Cardiff University, Cardiff, UK

Introduction The presence of increased numbers of $\mathrm{CD}^{+} \mathrm{T}$ cells in colorectal cancer (CRC) correlates with improved prognosis. However, it is difficult to measure anti-tumour responses in tumourinfiltrating lymphocytes (TILs) suggesting these cells are suppressed. Although we have demonstrated $\mathrm{CD}^{+}{ }^{+} \mathrm{Foxp}^{+}$regulatory $\mathrm{T}$ cells (Tregs) within the tumour and its stroma, the numbers are often low. We sought to identify phenotypic and functional characteristics of $\mathrm{CD}^{+} \mathrm{Foxp}^{-} \mathrm{T}$ cells to determine whether other regulatory populations exist within this environment.

Methods Tumour samples were obtained from CRC patients with different stages of malignancy. Fixed tumour samples were examined by immunofluoresence for CD3, CD8 and FoxP3. TILs from fresh tumour tissue were stained with a panel of 20 antibodies (including Helios, LAG-3, LAP) and examined by FACS.

Results Histology revealed tumours to be infiltrated by $\mathrm{CD}^{+}$, $\mathrm{CD}^{+}$and $\mathrm{Foxp3}^{+}$positive cells. Despite an increase in $\mathrm{CD}^{+}$and $\mathrm{CD}^{+} \mathrm{T}$ cells in advanced tumours, there was not always a concomitant increase in Foxp3 ${ }^{+}$cells. Flow cytometry revealed the majority of the Treg fraction was Helios ${ }^{+}$(indicating thymicallyderived) and expressed higher levels of CTLA-4 and CD39 than Tregs from colon and blood. However, $30 \%$ of "conventional" $\mathrm{CD}^{+}{ }^{+}$Foxp3 $^{-} \mathrm{T}$ cells express markers associated with Tregs including LAP (latency-associated peptide), LAG-3 and CD25 and were highly suppressive in vitro.

Conclusion Tumour-infiltrating $\mathrm{CD}^{+}{ }^{+} \mathrm{T}$ cells are heterogeneous. A high percentage of these cells appear to have a regulatory function and include both Foxp3 ${ }^{+}$as well as FoxP3 ${ }^{-}$T cells. Overcoming the suppressive environment of CRC is a major challenge for boosting anti-tumour immunity.

Competing interests None declared.

\section{PM0-089 PREOPERATIVE NEUTROPHIL: LYMPHOCYTE RATIO IS NOT A PREDICTOR OF OUTCOME FOLLOWING HEPATIC RESECTION FOR COLORECTAL METASTASES}

doi:10.1136/gutjnl-2012-302514b.89

C E Western, ${ }^{*}$ M Wiggans, S Aroori, M Bowles, D Stell. Department of Hepatopancreatobiliary, Derriford Hospital, Plymouth, UK

Introduction A high pre-operative neutrophil:lymphocyte ratio (NLR) has been shown in several studies to be associated with shorter disease-free and overall survival for a number of malignancies, including colorectal ${ }^{1}$ and both primary ${ }^{2}$ and secondary ${ }^{3}$ liver tumours. This may reflect reduced lymphocyte function, so impaired host response or neutrophil-mediated angiogenesis enhancing tumour spread and has been proposed as a prognostic predictor. ${ }^{1-3}$ We aimed to test this association by analysing preoperative NLR in all patients undergoing liver resection for colorectal metastases (CRM) and attempting correlation with tumour recurrence, overall and disease-free survival.

Methods Our unit is a tertiary referral centre for both laparoscopic and open hepatic surgery. A prospectively collected database of demographic details, radiological and histological findings and blood test results has been maintained since July 2005 and this data has been retrospectively analysed to demonstrate potential associations with NLR. An NLR > 5 was considered raised.

Results Between 15 July 2005 and 10 January 2012247 hepatic resections were undertaken for CRM. Median age at surgery was 67 (range 33-91) and 64\% were male. Overall median survival was 1818 days and overall median disease-free survival was 542 days. 125/247 (51\%) CRM developed recurrent disease within the followup period. Follow-up ranged from 10 days to 5.9 years (median 20 months). 30 patients had a NLR $>5$. When Kaplan-Meier analysis was performed to compare median survival in those with a low vs a high NLR, it was seen that there was no significant difference between the two groups $(p=0.81)$. There was also found to be no association between NLR and tumour recurrence $(p=0.49)$ or time to recurrence $(\mathrm{p}=0.77)$.

Conclusion Contrary to previously published studies, our unit has not demonstrated an association between pre-operative NLR and tumour recurrence or survival in patients undergoing liver resection for CRM and suggests that this is not a useful prognostic indicator in this group of patients.

Competing interests None declared.

\section{REFERENCES}

1. Hung HY, Chen JS, Yeh CY, et al. Effect of preoperative neutrophil-lymphocyte ratio on the surgical outcomes of stage II colon cancer patients who do not receive adjuvant chemotherapy. Int J Colorectal Dis 2011;26:1059-65.

2. Gomez D, Farid S, Malik HZ, et al. Preoperative neutrophil-to-lymphocyte ratio as a prognostic predictor after curative resection for hepatocellular carcinoma. World $\mathrm{J}$ Surg 2008; 32:1757-62.

3. Halazun KJ, Aldoori A, Malik HZ, et al. Elevated preoperative neutrophil to lymphocyte ratio predicts survival following hepatic resection for colorectal liver metastases. Eur J Surg Oncol 2008;34:55-60.

\section{PM0-090 GALECTIN-3 INDUCES SECRETION OF CYTOKINES FROM VASCULAR ENDOTHELIUM THAT ENHANCE CANCER CELL-ENDOTHELIUM ADHESION: A NOVEL MECHANISM FOR GALECTIN-3-MEDIATED METASTASIS PROMOTION}

doi:10.1136/gutjnl-2012-302514b.90

C Chen, ${ }^{*}$ Q Zhao, J M Rhodes, L G Yu. Department of Gastroenterology, University of Liverpool, Liverpool, UK

Introduction Galectin-3 is a galactoside-binding protein whose concentration is increased up to 31-fold in the bloodstream of patients with cancer including colorectal cancer. We have recently 